\title{
Resisting Gentrification: The Theoretical and Practice Contributions of Social Work
}

Amie Thurber

Portland State University

Amy Krings

Loyola University Chicago, akrings@luc.edu

Linda S. Martinez

Boston University

Mary Ohmer

University of Pittsburgh

Follow this and additional works at: https://ecommons.luc.edu/socialwork_facpubs

Part of the Social Work Commons

\section{Author Manuscript}

This is a pre-publication author manuscript of the final, published article.

\section{Recommended Citation}

Thurber, A., Krings, A., Martinez, L. S., \& Ohmer, M. (2021). Resisting gentrification: The theoretical and practice contributions of social work. Journal of Social Work, 21(1), 26-45

This Article is brought to you for free and open access by the Faculty Publications and Other Works by Department at Loyola eCommons. It has been accepted for inclusion in Social Work: School of Social Work Faculty Publications and Other Works by an authorized administrator of Loyola eCommons. For more information, please contact ecommons@luc.edu. (c) $($ () $\ominus$

This work is licensed under a Creative Commons Attribution-Noncommercial-No Derivative Works 3.0 License. (c) Sage Journals, 2019. 


\title{
Resisting gentrification: The theoretical and practice contributions of social work
}

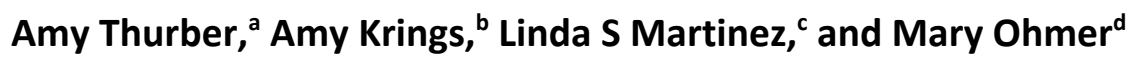

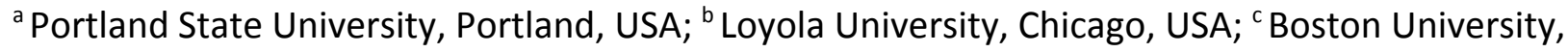 \\ Boston, USA; ${ }^{d}$ University of Pittsburgh, Pittsburgh, USA
}

\section{Corresponding Author}

Amie Thurber, athurber@pdx.edu, Portland State University, Portland, USA

\section{Copyright Agreement}

The Version of Record of this manuscript has been published and is available in Journal of Social Work, 2019, DOI: 10.1177/1468017319861500

\section{Complete Citation}

Thurber, A., Krings, A., Martinez, L. S., \& Ohmer, M. (2019). Resisting gentrification: The theoretical and practice contributions of social work. Journal of Social Work. DOI:

$10.1177 / 1468017319861500$

\begin{abstract}
Gentrification is changing the landscape of many cities worldwide, exacerbating economic and racial inequality. Despite its relevance to social work, the field has been conspicuously absent from scholarship related to gentrification. This paper introduces the dominant view of gentrification (a political economic lens), highlighting its contributions and vulnerabilities, then introduces four case studies that illuminate the distinct contributions of social work to broaden the ways in which gentrification is theorized and responded to within communities. When gentrification is analyzed exclusively through a political economy lens, researchers, policy makers, and practitioners are likely to focus on changes in land and home values, reducing the adverse effects of gentrification to a loss of affordable housing. A singular focus on affordable housing risks paying insufficient attention to racial struggle, perpetuating damage-based views of poor people and neighborhoods, and obfuscating political, social, and cultural displacements. Social work practice-including social action group work, community organizing, community development, and participatory research and planning-offers a holistic approach to understanding, resisting, and responding to gentrification and advance equitable development in the city. By exploring social work practice that amplifies residents' and change makers' efforts, advances existing community organizing, produces new insights, builds inter-neighborhood and interdisciplinary collaborations, and facilitates social action and policy
\end{abstract}


change, this paper helps community practitioners to reimagine the role of social work research and practice in gentrifying neighborhoods.

KEYWORDS: Social work, community development, housing, social policy, social work practice, ethnic minorities 


\section{Resisting gentrification: The theoretical and practice contributions of social work}

Amy Thurber, Amy Krings, Linda S Martinez, and Mary Ohmer

In developing cities across the globe, residents and housing advocates are sounding alarms in response to rapidly rising land values and the diminishing pools of affordable housing. This spatial and social transformation is commonly referred to as gentrification. Although definitions vary, Davidson and Lees (2005) suggest gentrification is distinguished by four key characteristics: (1) reinvestment of capital, (2) increase in high-income demographics, (3) landscape change, and (4) direct or indirect displacement of low-income groups (p. 1187). In the United States, urban neighborhoods are gentrifying at twice the rate of the 1990s, with one in five low-income neighborhoods experiencing rapid increases in median home values, and cities nationwide reporting affordable housing crises (Maciag, 2015). A recent study by the National Low Income Housing Coalition (Aurand, Emmanuel, Yentel, \& Errico, 2017) found the United States currently has a 7.4 million unit shortage in affordable housing. Though multiple factors contribute to this gap, the shortage is most severe in states experiencing gentrification. Similar patterns of soaring housing values and shrinking affordability have been documented in Canada and the United Kingdom (Owen, 2015; Sturgeon, 2016). Given social work's commitment to pay "particular attention to the needs and empowerment of people who are vulnerable, oppressed, and living in poverty" (National Association of Social Workers, 2017), the field has a distinct responsibility to intervene in gentrifying neighborhoods. Indeed, addressing gentrification aligns with The United Nations' Sustainable Development Goals, which call upon governments, business, and civic leaders to develop and implement measures that reduce poverty and economic inequality while fighting climate change (https://www.un.org/sustainabledevelopment /sustainable-development-goals). Similarly, within the United States, the Academy of Social Work and Social Welfare recently launched a call to action, establishing 12 grand challenges for social work (http:// aaswsw.org). Many of these challenges - ending homelessness, reducing extreme economic inequality, achieving equal opportunity and justice, eradicating social isolation, and closing the health gap — are deeply tied to neighborhoods. And yet, social work has been conspicuously absent from public conversation about gentrification.

A Prosearch query for peer reviewed articles on gentrification returned 2438 manuscripts published between 2000 and 2018. Less than 1\% were published in social work journals. While it may be that social workers are publishing in other disciplinary outlets, or are investing their time in practice rather than dissemination, the absence of relevant literature in our field's journals suggests a lack of engagement with one of the most pressing phenomena facing neighborhoods today. Thus, we contend that social work scholars face an opportunity to model and study innovations in confronting gentrification.

To that end, in the pages that follow we introduce the contributions and limitations of the dominant (political economic) view of gentrification, which is useful in understanding 
gentrification's causes, but often reduces its consequences to a loss of housing. We suggest adopting a critical race and feminist lens to expand understanding, then offer four case studies of social work practice in gentrifying neighborhoods. We note that although each case is located in a different region within the US, they each draw upon traditional social work methods including social action group work, community organizing, community development, and participatory research and planning. To conclude, we highlight social work's contributions to how gentrification is theorized, and responded to, in service to advancing equitable development in the city.

\section{Contributions and limitations of a political economy lens}

The predominant explanation of gentrification draws on a political economic analysis. In this view, gentrification is the predictable result of capitalism, as manifest in the current era of neoliberalism (Lees, Slater, \& Wyly, 2013). Neoliberalism refers to a specific ideology and associated practices of governance that prioritize free market principles in public life, and the rollback of social welfare and regulations intended to protect people and land from exploitation (Abramovitz, 2012; Harvey, 2005). Under neoliberalism, geographies of varied scales (including global regions, nation-states, cities, and neighborhoods) are constructed through processes of uneven development, in which some places are systematically less developed while others are more developed (Brenner \& Theodore, 2002). This serves a variety of functions for economic elites: people and places within underdeveloped areas can more easily be exploited for land, resources, and labor; the existence of "undesirable" areas creates a market for high-cost alternatives; and - following the logic of buy low, sell high — deferring development in some regions ensures a high return on investment if the area is later strategically developed. Further, regions may experience cycles of investment and divestment in order to provide new opportunities for wealth production (Brenner \& Theodore, 2002; Smith, 1996).

The functions of uneven development can be seen in the context of gentrifying urban areas: many neighborhoods that are home to low-income and poor residents have experienced systemic public and private divestment (such as government's failure to allocate sufficient resources to maintain public housing and the outsourcing of manufacturing jobs). Such divestment suppresses land prices, making the areas vulnerable to speculators. When targeted with intense investment, these same areas experience rapidly rising land values, which produces profits for speculators and depletes the affordable housing stock (Smith, 2002).

\section{Tracing displacement and making the case for affordable housing}

Analyzing gentrification through a political economy lens illuminates exactly who it helps and who it harms, and highlights gentrification's most obvious consequences for poor and working-class people: displacement and the lack of access to affordable housing. Indeed, tracing displacement has been a core focus of gentrification literature since the 1960s (Glass, 1964; Marcuse, 1985; Zuk et al., 2015). Thanks to efforts to expose the relationship between some 
forms of urban revitalization and a loss of affordable housing, many cities are adopting strategies to advance equitable forms of development in revitalizing areas. For example, more than 500 jurisdictions in the United States now have inclusionary housing policies. Such policies increase affordable housing by incentivizing or requiring the construction of a proportion of affordable housing units relative to the number of market-rate units within multi-unit housing developments (Hickey, Sturtevant, \& Thaden, 2014).

Critically, efforts to mitigate the displacement effects of gentrification have been strongly contested by many developers and policy makers, a number of whom champion gentrification's supposed benefits to both places and people. As reflected in headlines such as "Bring on the Hipsters: Gentrification is Good for the Poor" (2015), the conflation of revitalization and gentrification has had broad uptake in popular culture. Such narratives legitimize a wide range of zoning practices, policies, and strategies that encourage unfettered development (Moskowitz, 2017). For example, 42 U.S. states have passed preemptive legislation prohibiting rent control mechanisms or banning inclusionary housing policies (https://www.nmhc.org/research-insight /analysis-and-guidance/rent-control-laws-by-state/). Clearly, political struggles to meet the housing needs are hard fought and many are not won.

\section{A need for expanded theory and intervention}

When gentrification is analyzed exclusively through a political economy lens, researchers, policy makers, and practitioners focus on changes in land and home values, and reduce the adverse effects of gentrification to a loss of affordable housing. This approach implies that building and preserving affordable housing is the antidote to gentrification. While in no way contesting the need for affordable housing, we contend that such a narrow policy agenda pays insufficient attention to racialized policies and their resulting inequities, perpetuates damage-based views of poor people and neighborhoods, and disregards other losses (such as erosion of community and damaged place attachments). Though these three limitations are related, we introduce them in turn.

First, the predominant view of gentrification pays insufficient attention to the disparate impact of gentrification on communities of color. The absence of a racial analysis is evident in the proclamation by Lees et al. (2013) that "gentrification is nothing more and nothing less than the neighborhood expression of class inequality" (p. 80). This analysis ignores the entangled relationship between neoliberalism and the racialization of space that informs where and how gentrification manifests, and also fails to account for the particular risks borne by people of color in gentrifying neighborhoods. This is not to suggest gentrifying neighborhoods are only inhabited by people of color or incomers are always white. However, given the racialization of space - which can be understood as the spatial ideologies, policies, and practices that have segregated and/or systematically removed people of color (Lipsitz, 2007) — people of color are more likely to live in neighborhoods vulnerable to gentrification and thus are disproportionately harmed (Kennedy \& Leonard, 2001). To address the particular impacts of gentrification on 
communities of color requires the adoption of a critical race lens, that is a commitment to tracing how race and power shape society (Crenshaw, Gotanda, \& Peller, 1995). Indeed, a number of scholars are now mapping the intersections of race, class, and place to document the particular effects of gentrification on communities of color (e.g., see Gibson, 2007; Li, Vitiello, \& Acoca, 2013).

Second, displacement-focused gentrification scholarship (often inadvertently) pathologizes marginalized communities, such as people of color and the poor. Case studies of gentrifying areas often follow a familiar narrative arc: After generations of systemic disinvestment, white flight, and government neglect, an urban neighborhood is "revitalized," driving up property values and displacing poor and low-income residents. Yet casting pre-gentrified low-income neighborhoods as places of disinvestment masks generations of investment made by residents themselves, including the creation of vibrant social networks, place-based collective economic models, and neighborhood improvement projects. Further, damage-based narratives ignore aspects of neighborhoods that residents value and are committed to preserving. Critical geographer Katherine McKittrick (2011) cautions against relying on narratives "wherein particular communities and their geographies are condemned to death over and over again," noting such "analyses of racial violence leave little room to attend to human life" (p. 954). As feminist scholars have long argued (Rose, 1993), all geographies must be explored as contested sites. In gentrifying neighborhoods, such exploration involves documenting the multitude of ways residents resist displacement and continue to create community alongside and within harmful processes of spatial transformation (Cahill, 2006; Nam, 2012).

A third vulnerability to the political economy approach is a disregard for losses other than housing. Gentrification not only impacts where people live, but also may affect where people work, study, socialize, shop, congregate, agitate, worship, and bury their dead. Gentrifying communities may experience root shock, which is the traumatic stress related to the long-term effects of the removal and/or destruction of large parts of one's neighborhood and environment (Fullilove, 2004). As detailed by psychiatrist and public health scholar Mindy Fullilove (2004), the physical destruction of neighborhoods produces a constellation of losses, including the loss of generational knowledge, social networks, place attachments, and civic engagement. In her study of one such community disrupted by Urban Renewal in the 1950s and 1960s, Fullilove (2004) concludes that "the loss of collective capacity to solve problems in order to make progress became ... permanently crippling" (p. 99). Gentrification similarly produces a battery of potential harms. As such, there has been a shift toward examining the "more than material" (Thurber, 2018) effects of gentrification, including the political, social, and cultural displacements which may occur whether or not residents are physically displaced (Davidson, 2008; Hodkinson \& Essen, 2015; Twigge-Molecey, 2014). For example, gentrification frequently involves social elites taking control of and re-narrating historical meanings of a place (Chidester, \& Gadsby, 2009) and other forms of symbolic erasures, such as changing 
place-names (Hodkinson \& Essen, 2015). Such actions can be understood as epistemic injustice (Medina, 2013); they function to ignore the knowledge, contributions, and desires of long-term residents - even as they remain in place - while legitimating their exclusion from participation in civic life.

In summary, despite the utility of political economy explanations of gentrification, and the urgency to address housing needs, there are significant limitations to centering policy agendas exclusively on affordable housing: it pays insufficient attention to racial inequity, perpetuates damage-based views of poor people and neighborhoods, and obfuscates the range of displacements residents may experience. Infusing a political economy perspective with a critical race and feminist stance, we ask: What might a more holistic approach to understand, resist, and respond to gentrification look like?

Given social work's recognition of the biological, social, cultural, psychological, and spiritual dimensions of well-being, the field is well-positioned to help expand conceptualizations of gentrification's effects. In addition, community practice social workers employ a range of interventions that may be relevant in gentrifying neighborhoods: community organizing (i.e. neighborhood, labor, cultural, and rights-based organizing), community development (i.e. economic, housing, and social development), planning (i.e. design of effective interventions on a variety of scales), and systems change (i.e. legislative and media advocacy, political and social action, and action research) (Brueggemann, 2014). Linking theory to practice, social work can help deepen collective understanding of the consequences of gentrification-including and in addition to a loss of housing - and expand the possibilities for intervening in gentrifying neighborhoods.

\section{Case studies}

Although gentrification has been studied extensively in other disciplines, the contribution of social work is an under-investigated topic for examination. Therefore, we present a set of exploratory case studies that consider opportunities for social workers to intervene within gentrifying neighborhoods. By using a multiple-case design (Stake, 2006), we identify general themes to help us understand the larger phenomena of social work and gentrification. The following four cases document social work practice in gentrifying neighborhoods:

1. The Neighborhood Story Project, a place-based intervention that engages residents in addressing epistemic, social, and political displacements in Nashville, Tennessee.

2. A partnership with an environmental justice organization in Chicago, Illinois working to improve community access to green spaces without contributing to residential displacement.

3. An action research partnership exploring the health effects of gentrification in Boston, Massachusetts.

4. A community-engaged teaching/learning project that joined students and neighborhood change makers to document the effects of gentrification and advocate for policy 
responses in Pittsburgh, Pennsylvania.

These cases were selected because they offer insights into how social workers can apply a critical race lens to understand the racialized impacts of neighborhood change, to highlight resident resistance and agency, and to explore multiple consequences of gentrification. In addition, the cases demonstrate possibilities of intervention at a variety of scales (from a single neighborhood to a constellation of neighborhoods within a large metropolitan area) as well as multiple practice methodologies (including group work, community organizing, community development, and participatory research and planning). All cases used a combination of data collection methods including participant observation, interviews, and document analysis. As the four authors present a case from our respective practice, each case is presented in first person with the author noted at the outset.

\section{Engaging residents as change agents in Nashville, Tennessee}

Currently ranked among the fastest growing cities in the nation (Nelson, 2013), Nashville has lost more than $20 \%$ of its affordable housing stock since 2000 , and $30 \%$ of county residents cannot afford the cost of housing (Office of the Mayor, 2017). Gentrification has hit the city's historically black neighborhoods particularly hard. Over several years working alongside residents, I (Amie) learned that in addition to concerns about the loss of affordable housing, many were deeply troubled by an atrophied sense of social cohesion, the loss of collective history, and a depleted sense of agency to affect community change. I designed the Neighborhood Story Project to help residents study the changes taking place in their neighborhoods and develop a strategy to improve their communities.

\section{Practice: Using social action groups to facilitate resident learning and action. The}

Neighborhood Story Project bridges group work and participatory action research. Each project begins with the recruitment of 8-12 residents committed to participate in a 12-week facilitated process. Members generate a series of research questions about their neighborhood, then collect data to explore their questions and analyze what they find. Each project culminates with a community event, where members disseminate what they have learned to the broader community (Thurber, 2019).

Between February and December 2016, I facilitated the Neighborhood Story Project in three gentrifying neighborhoods of Nashville, Tennessee: Cleveland Park, Edgehill, and the area around Stratford High School. Each of these is a historically black neighborhood where housing values are now increasing at rates more than twice the city-wide average (Thurber, 2019). Participants were predominantly long-time residents who had concerns about the changes in their community. However, each group identified different research questions, types of data to collect, and approaches to dissemination.

Members of the Cleveland Park Story Project were concerned about fractured social cohesion and lost sense of history. As one member said, "some of the new people, I know they're 
only there for a short time ... but there is like a ripping of the fabric of the neighborhood when you kind of dive in and dive out" (project participant). Worried this ripping of their neighborhood was disproportionately harming elders, low-income residents, and residents of color, this team's primary research questions was: How can we make Cleveland Park home again? To explore this question, members recorded conversations with 17 neighbors of various tenures, gathered historic and contemporary images from the neighborhood, and analyzed archival materials. The project culminated with a multimedia interactive exhibition attended by approximately 50 neighbors, and the exhibit remained in the community center for several months before being archived online.

Across the city, members of the Edgehill Story Project were deeply troubled that gentrification was breaking apart the neighborhood. As Ms TK explained,

the people that you have been growing up with all your life ... a lot of them, they had to move on. We are like, 'well darn, I feel so naked. So lost without my other people, and without my neighborhood.' That is one of my concerns, that we do not lose each other because we matter for each other. (Project participant)

In response, the Edgehill team sought to answer the research question: what is driving development and the displacement of our neighbors, and how can we intervene? The team gathered data related to home values, demographics, evictions, and foreclosures, and resources to help renters and homeowners remain in their homes. They also interviewed their neighbors. Their final products included a 20 minute video to be used as an educational and organizing tool, and a report that included a comic strip that explained how zoning works and how community members can advocate against unwanted development (https://edgehillstateofemergencyreport. wordpress.com/). The video and report were released at a highly attended neighborhood "call to action," and resulted in increased neighbor involvement in anti-displacement organizing.

The third Neighborhood Story Project centered within a school zone, and members included students, alumni, parents, and neighbors of Stratford High School. Opened as an all-white school in the 1960s, Stratford High School has weathered years of challenges: court-ordered desegregation, white flight, disinvestment, high staff turnover, and student struggles to succeed in school. Outside the school, many Nashvillians associated these difficulties with the student population rather than with structural inequity, and the school and its predominantly black student body were stigmatized. With gentrification, the school zone has become wealthier and whiter. The Stratford Story Project team was concerned that the history of the school was being reduced to a racialized narrative: this was a good school when it was all white, a bad school when it was all black, and it now is getting better again because of more white families moving in. Ultimately, the Stratford Story Project asked: how has the changing reputation of Stratford impacted people's investment in the school, and how can we change it for the better? Members collected interviews from students and teachers from every decade of the 
school's history, along with archival data, and wove these into a feature-length documentary film, "A Stratford Story" (https://www.youtube.com/watch?v1/4nA9AB Pw3Z18\&t1/4184s). The film has since been shown at a number of neighborhood functions, incorporated into Stratford courses, and reached more than 2500 people online.

Impact: Centering resident experiences and seeding collective action. The range of Neighborhood Story Projects offer an important reminder that gentrification, while widespread, may be experienced differently in various neighborhoods within the same city. Some residents may be concerned about fractured relationships, others with lost housing, and still others with stigmatizing narratives. Group-level interventions such as this one can account for these differences. As such, the Neighborhood Story Project offers one practice model to engage residents of gentrifying neighborhoods to explore the particular harms their neighbors may be experiencing and take action to respond to change those conditions.

\section{Advancing environmental justice while resisting gentrification: Chicago, Illinois}

The Little Village Environmental Justice Organization (LVEJO) engages in participatory methods including democratic planning, grassroots community-based campaigns, and community development to advance environmental justice and the self-determination of immigrant, low-income, and working-class families (http:// lvejo.org/our-mission/mission -vision-statement). It is based in Little Village, a predominantly Mexican-American neighborhood on the southwest side of Chicago, Illinois. The neighborhood hosts a rich diversity of family-owned businesses and restaurants, murals, and cultural activities. However, it is also home to several locally undesirable land uses (LULUs) such as the Cook County Jail, a major interstate, manufacturing plants, and brownfield sites. These LULUs contribute to environmental and health impacts due to a lack of green spaces and clean air.

To address environmental injustices within the neighborhood, LVEJO has organized and been part of a number of successful campaigns (Kern \& Kovesi, 2018). It has secured the expansion of safe and reliable public transportation, the closure of a local coal-fired power plant, and facilitated community-led participatory planning processes that shaped the development of community gardens and the La Villita Park. These campaigns have improved the quality of life among residents by drawing upon local leadership and expertise.

\section{Practice: Supporting ongoing community organizing and participatory planning. As an} assistant professor of social work whose teaching and scholarship center on the community engagement of marginalized groups, I (Amy) was invited by a colleague, Tania Schusler, to join her class on a LVEJO-led tour of Little Village. I was inspired by LVEJO's good work and, afterward, my colleague (who teaches and researches environmental justice activism through my university's Institute for Environmental Studies) and I asked LVEJO leadership if there were ways we could support their campaigns through research and student engagement. The LVEJO 
leadership described growing concerns about gentrification in the neighborhood and asked us to research examples of community resistance. In particular, LVEJO was concerned about the construction of El Paseo, a bike trail proposed by the mayor's office to connect Little Village with Pilsen, a rapidly gentrifying Mexican-American neighborhood that borders Little Village (Greenfield, 2016). The leadership of LVEJO was prepared to oppose the proposal because it did not include a participatory planning process and consequently some wondered whether it would exacerbate gentrification. As LVEJO's executive director explained, "Folks who fought for [environmental improvements] should be able to stay in the neighborhood and enjoy them" and "unless [the city does] this project in a holistic manner, we may find ourselves on opposite sides of the issue" (Greenfield, 2016). According to the leadership of LVEJO, the project's developers responded to these concerns by characterizing LVEJO as irrational for opposing a bike path while claiming to advance environmental justice.

As my colleague and I began to research the issue, we quickly found a name for LVEJO's fears: green gentrification. Green gentrification refers to situations in which the cleanup of undesirable land uses and/or the installation of green amenities drives up real estate prices, contributing to the displacement of working-class or poor residents (Checker, 2011). Like all forms of gentrification, green gentrification is controversial because it can benefit and burden residents at the same time. Although green amenities can result in upgrades to housing stock, neighborhood beautification, and increased community safety, they can also lead to increased rents, decreased economic diversity, and displacement or exclusion of lower income groups and community culture (Dale \& Newman, 2009). The LVEJO organizers were not irrational as the city's planners suggested. Instead, they faced a strategic dilemma: How can environmental justice advocates reduce contamination and secure accessible green spaces without displacing existing residents? After all, if fighting for a clean community has the unintended result of displacing the very residents meant to benefit from these campaigns, LVEJO would reproduce environmental injustices.

Impact: Expanding the scope of environmental justice activism. As requested, my colleague and I produced a technical report that summarized literature about (1) relationships between urban greening, brownfield redevelopment, and gentrification; (2) policy mechanisms that can prevent gentrification and/or mitigate its negative impacts; and (3) strategies that other community organizations in the United States have used to promote environmental health without displacing people (Schusler \& Krings, 2018; Schusler, Krings, Asis, \& Fitzpatrick, 2017). The LVEJO leadership team used these findings to bolster its demands: the trail should include community gathering spaces, public art, and gardens; celebrate Latinx culture; and prioritize residents for employment in associated jobs (Wisniewski, 2018). City officials have stated that they agree with these positions and local aldermen in the area have considered the possibility of limiting housing development along the trail to protect long-time residents (Wisniewski, 2018). Although the proposed trail is presently on hold, LVEJO continues to build 
new collaborations with affordable housing groups to promote environmental justice in a way that explicitly preserves local culture and protects the right of existing residents to stay (Kern \& Kovesi, 2018).

\section{Integrating a health lens into gentrification dialogue in Boston, Massachusetts}

Historically, gentrification conversations in Boston have largely occurred in the context of affordable housing, leaving unexplored its far-reaching impacts on community health and well-being. The purpose of this project was to engage residents of two rapidly gentrifying neighborhoods in Boston-Roxbury and Jamaica Plain - to explore how gentrification impacts health. In both areas, the Latinx population is predominantly Dominican and Puerto Rican. Over the last two decades, Jamaica Plain has shifted from a majority low- to moderate-income Latinx neighborhood to a moderate income to affluent white neighborhood, with pockets of subsidized affordable housing sites that are home to people of color who are predominantly Latinx. In contrast, people of color, including Caribbean Latinx, African Americans, Cape Verdeans, and Somalians, make up the majority of Roxbury. This case describes a community-academic partnership initiated by the Dominican Development Center (DDC), a grassroots advocacy and organizing group focused on empowering immigrants in Boston neighborhoods through education, advocacy, and social action.

Practice: Centering resident voice to understand gentrification's effects. Myself (Linda) and macro social work field placement students, along with a colleague from the Department of Public Health and Community Medicine at Tufts University, partnered with the DDC to launch this action research study. To begin, we assembled a diverse team (including Dominican youth and adult residents, macro social work students, educators and staff from the DDC) to study the effects of gentrification in the neighborhoods from a variety of perspectives. The DDC director identified key stakeholders for students to interview, including organizers, housing advocates, and community and economic development professionals who work with Latinx residents. Additionally, the DDC director and I co-facilitated two focus groups with residents and interviewed business owners in the neighborhood. The students and I recorded and transcribed all of the interview and focus group data, and then coded them thematically.

The study revealed gentrification is an important determinant of community health. There was an overwhelming feeling that those who had "made the community what it is" or "fought for the community" were being systematically removed from the community. As one person explained,

... neighborhoods are improving because of really great community organizing ... And ... all of a sudden ... those who didn't want to live there before ...suddenly said, "Oh! You guys made this place a really nice place to live, let me buy your house from under you.” (Participant \#0004) 
Participants were acutely aware of a pattern in which neglected neighborhoods populated by low-income people of color become desirable, leaving residents - once excluded from city revitalization - priced out. They understood this as a racialized process that is both systematic and intentional.

In addition to the loss of housing, our research found that gentrification reduced residents' access to resources including transportation, education, and health care, all of which can negatively impact mental health:

If you can no longer afford to live where you have been living ... you have to figure out how you can afford to live somewhere else, and that's a huge stress factor on people, ... you have to move further away and ... cost of public transportation goes up, ... it just impacts every aspect of their lives he stress is a huge factor that is underestimated. ... (Participant \#0009)

As reflected in this quote, residents displaced by gentrification are cut off from their social and familial networks and have to navigate new systems that in many cases are already overburdened.

We also found that not all low-income residents are physically displaced. Many participants described doubling or tripling up with other families to be able to pay the rent and remain in the city. This can affect public health because of the association between overcrowding and the transmission of illness (Aligne, 2016). Several residents reflected on the stress doubling up created in families, especially for children. Those left behind in gentrified communities also described social and cultural marginalization. For example, one participant shared, "The feel of the place has changed dramatically. The town space, the use of outdoor space, it's a very different feeling on the street ... and people feel like they're not at home anymore" (Participant \#0001e).

Older adults, particularly those at low-income housing sites, identified social isolation as contributing to depression and feelings that they could not move about the community because it was no longer theirs. One woman reflected on no longer being able to walk down the street to chat with people on their porches. Residents also described how rising prices in local markets limited their ability to shop locally, as well as how local stores no longer offered Caribbean produce. For many, this meant having to travel outside of the community for resources.

Following data analysis, our research team shared the key themes with our research partners and planned a community forum to discuss strategies to promote healthy community development. Sixty-five people attended, including a diverse mix of black and Latinx residents, academics, public health and medical professionals, and elder and housing advocates, as well as grassroots organizers and municipal employees. At the forum, colleagues from Tuft and the DDC and I shared our findings related to health and well-being and other groups also shared 
their insights. Following these presentations, forum participants discussed strategies for building coalitions between organizations, municipal leaders, and residents; recognizing social and cultural displacement in addition to physical displacement; and including residents - especially elders, youth, and people of color - in the decision-making process. Participants also identified the need for policies to generate affordable housing and incentivize landlords to subsidize rent costs, opportunities to work more closely with developers, and the need for transparent and accessible data collection systems.

Impact: Catalyzing new collaborations and conceptualizations. Exploring gentrification through a health lens opened the door for the DDC and their partners to engage diverse stakeholders and residents in community conversations related to gentrification. Since the community forum, my students and I have worked with public housing residents on efforts to reclaim community spaces and have continued to organize neighborhood dialogues about health impacts of gentrification. Research partnerships are an important tool for supporting the work of local organizers and community advocates; social work, specifically, is well-poised to lead in this space, serving as an important bridge between public health, human services, and community development agencies. In this case the DDC, along with social work and public health researchers and students, was able to bridge community groups and municipal leadership to catalyze an important conversation.

\section{Mobilizing community change makers toward equitable development in Pittsburgh, Pennsylvania}

Over the last decade, Pittsburgh neighborhoods that formerly housed poor and working-class people, and people of color have experienced significant changes related to gentrification. Formerly divested areas in the city have become targets for gentrification because of their proximity to downtown, local universities, and affluent areas. As property values and rents have increased at alarming rates, long term residents and businesses have been displaced, and city and neighborhood leaders have struggled to adapt to this shift. Unlike rapidly growing cities impacted by gentrification, such as New York City or San Francisco, Pittsburgh's population was on the decline for decades and has only stabilized in the last five years (Rotstein, 2015).

Practice: Employing action research to generate collective action. For this project I (Mary) worked alongside my MSW students to engage community leaders from across Pittsburgh around their growing concerns related to gentrification and displacement. Our goal was to surface common issues across nine neighborhoods and to develop policy solutions that might prevent the negative effects of gentrification and promote equitable development. We focused on engaging representatives of community planning and development organizations who were working to promote equitable revitalization in their communities (change makers), as well as 
policy makers and staff of city-wide philanthropic and government organizations (policy makers).

This project involved MSW students in two courses, Community Organizing and Community Planning and Development. Students conducted interviews with 20 change makers and 13 policy makers; interviews were audio or video recorded, transcribed, and summarized. The interview guide included questions such as (1) What major changes have occurred in the past decade that you believe have had the most impact on neighborhood revitalization and change in Pittsburgh? (2) What organizational efforts, if any, are you working on that support neighborhood revitalization but also curb displacement? (3) What policies and/or programs do you feel would be helpful in this regard? In addition, students gathered demographic data on the nine neighborhoods and compiled scholarly research on best practices related to mitigating displacement and increasing community engagement in city planning and development.

The interviews revealed a broad recognition that, although gentrification pressures affected only some neighborhoods, it was important to develop proactive city-wide strategies that support revitalization while preserving neighborhoods and their culture. One change maker explained that the "house flipper culture" (buying a house with the intent to sell it for a profit) and the proliferation of major housing developments without affordable units are "creating incredible pressure for us to try and balance that historical sort of fabric of the neighborhood, [and] what is a clear departure [from what it once was]" (Community Development Corporation Leader).

Following initial data collection, we organized a Dialogue on Neighborhood Change that was attended by interviewees and other change makers. After students presented their findings, participants discussed their experiences of neighborhood changes, including the increasing cost of housing, displacement of residents in gentrifying areas, and accelerating income and racial disparities. Participants identified potential policy interventions, including community land trusts and inclusionary housing, as well as equitable workforce and business development policies. They also realized the necessity of accountability measures. As one person noted

Projects often have certain targets attached such as providing a certain percentage of affordable units or seeking out minority-owned businesses and local workers. While some developers follow through, there is no requirement or punishment when specific targets to prevent gentrification are not achieved. (Community Development Leader)

Ultimately, participants recognized the power of working across neighborhoods to advocate for policy changes, as such coalitions can provide a critical source of accountability.

Impact: Advancing equitable development policies. Since the Dialogue on Community Change, a number of policies recommended by change makers have moved forward, including (1) 
community land trusts in targeted neighborhoods across the city, (2) a \$10M Housing Opportunity Fund created by the city of Pittsburgh and supported by an increase in the tax on property sales (Bauder, 2018), and (3) an Equitable Development Strategy for Pittsburgh developed by local change makers and city leaders in cooperation with Policy Link, a national research and action institute advancing economic and social equity (http://www.policylink.org; Truehaft, 2016). I have continued work with change makers to further this research and develop action steps, including engaging other residents and incorporating their perspectives. This project demonstrates how social work educators can integrate current issues like gentrification and equitable development into their courses through applied projects. These projects provide students with meaningful research experience while also helping the city's community development leaders identify common issues and develop solutions that generate momentum for local equitable development policy strategies.

\section{Discussion}

In many cities grappling with gentrification, social workers already play a critical role in helping people locate and keep affordable housing. This work is needed and yet insufficient given the lack of affordable housing stock in many communities. These cases illustrate a variety of other ways social workers may engage in gentrifying neighborhoods: to amplify residents' and change makers' efforts, advance existing community organizing, produce new insights, build inter-neighborhood and interdisciplinary collaborations, protect and expand affordable housing, and facilitate social action and policy change. As evident in the case studies above, some communities may be actively trying to prevent gentrification, others trying to resist it, and still others may be concerned with documenting what has already been lost. Whatever the goals of a given community, social workers can leverage our resources to address the harms of gentrification and work toward more just communities.

In addition to practice contributions, social workers can meaningfully advance the state of gentrification scholarship. In each of the four case studies, rather than ignore legacies of racial oppression, social workers engaged communities of color as research partners and collaborators. Long-time residents and community change agents contributed insights into contemporary experiences of racism in the neighborhood, as well as contextual knowledge about how community members have resisted racism over time. In some cases, neighborhood-based interventions provided the opportunity for residents to tailor civic action to their specific concerns and experiences. In others, social workers helped form coalitions across neighborhoods to build power for change.

In place of perpetuating damage-based views of poor people and neighborhoods, these cases surface how social workers can center community member's knowledge, hopes, and agency to affect change. This is not to say all residents have the same perspectives, but rather these perspectives - convergent or otherwise - can sharpen our collective analysis of how gentrification manifests in a particular time and place. Similarly, instead of ignoring the "more 
than material" consequences of gentrification, social workers recognized the range of concerns residents raised. Although the loss of housing was a chief concern across the cases, so too were ruptures of social ties, damaging narratives of place, and threats to environmental health and mental and physical well-being. The recognition set the stage for innovative, community-engaged interventions.

\section{Limitations}

Although there are unmet opportunities for social work practitioners and scholars to engage within gentrifying neighborhoods, literature on the topic is sparse. Thus, to begin to address this gap, we chose an exploratory multiple-case research design (Stake, 2006). Although this methodology offered insights into possible social work interventions within four unique contexts with varying practice methodologies, our findings are nonetheless limited in their generalizability. Specifically, as gentrification impacts - and is resisted by - communities across the globe, there is a need to document to share best practices within different political economic contexts.

\section{Conclusion}

Returning to the question, what might a more holistic approach to understand, resist, and respond to gentrification look like?, we find value in leveraging the contributions of a political economy lens, which recognizes that our practice is constrained by the broader economic and political system. Although several of our cases illustrate progress in advancing equitable development and affordable housing plans, and stalling questionable development, accountability will require continued pressure. Social workers can help equip residents with the skills and strategies to advocate for desired changes, and to organize to ensure that hard-fought agreements materialize.

At the same time, a holistic approach also leverages critical race perspectives in order to attune to the distinct impacts gentrification has in different neighborhoods, and on different population groups within a neighborhood. Such an approach helps us to differentially attend to the needs of those who are pushed out and those who remain and may be isolated within their own communities, and to recognize others who benefit from community change. There is a critical need to reimagine the role of social work in gentrifying neighborhoods beyond only helping people find or keep housing. This article begins to address this gap, highlighting how social work can amplify resident experiences and desires, strengthen community organizing, facilitate community-engaged planning and research, and advance equitable policies. Importantly, social work can help broaden the study of gentrification beyond locating its structural causes to understanding possibilities for-and lending our hands to-local resistance.

\section{Ethics}

The Neighborhood Story Project received IRB approval from Vanderbilt University (\#160024). 
The LVEJO case did not include an IRB because it drew upon secondary data. The action research partnership in Boston was determined to be exempt from human research ethics approval by the Tufts University Social Science, Educational and Behavioral IRB (protocol\#1504020). The University of Pittsburgh case did not include IRB because it was a class project.

\section{Funding}

The authors disclosed receipt of the following financial support for the research, authorship, and/ or publication of this article: The Neighborhood Story Project was supported by funding from Humanities Tennessee, the Metropolitan Nashville Arts Commission, and the Curb Center for Art, Enterprise and Public Policy at Vanderbilt University. The community-academic partnership between the DDC, Boston University and Tufts University was funded by the Tufts University Community Research Center. The University of Pittsburgh case study was supported by the Community, Organization and Social Action Program at the School of Social Work.

\section{Acknowledgements}

The authors offer gratitude to the anonymous reviewers whose recommendations helped us to clarify our thinking and improve this manuscript.

\section{References}

Abramovitz, M. (2012). The feminization of austerity. New Labor Forum, 21, 30-39.

Aligne, C.A. (2016). Overcrowding and mortality during the influenza pandemic of 1918 : Evidence from US Army Camp AA Humphreys, Virginia. American Journal of Public Health, 106(4), 642-644. doi:10.2105/AJPH.2015.303018

Aurand, A., Emmanuel, D., Yentel, D., \& Errico, E. (2017). The gap: A shortage of affordable homes. Washington, DC: National Low Income Housing Coalition. Retrieved from https://nlihc.org/sites/default/files/Gap-Report_2017.pdf

Bauder, B. (September 6, 2018). Pittsburgh housing fund board recommends program funding levels for 2018. Tribune-Review.

Brenner, N., \& Theodore, N. (2002). Cities and the geographies of "actually existing neoliberalism." Antipode, 34(3), 349-379. doi:10.1111/1467-8330.00246

Bring on the Hipsters: Gentrification is Good for the Poor. (2015, February 21). The Economist. Retrieved from http://www.economist.com/news/united-states/

21644164-gentrification-good-poor-bring-hipsters

Brueggemann, W. (2014). The practice of macro social work (4th ed.). Belmont, CA: Brooks/ Cole, Cengage Learning.

Cahill, C. (2006). "At risk"? The fed up honeys re-present the gentrification of the Lower East Side. Women's Studies Quarterly, 34(1/2), 334-363.

Checker, M. (2011). Wiped out by the "greenwave": Environmental gentrification and the 
paradoxical politics of urban sustainability. City \& Society, 23, 210-229.

Chidester, R. C., \& Gadsby, D. A. (2009). One neighborhood, two communities: The public archaeology of class in a gentrifying urban neighborhood. International Labor and Working-Class History, 76(1), 127-146. doi:10.1017/S0147547909990123

Crenshaw, K., Gotanda, N., \& Peller, G. (1995). Critical race theory: The key writings that formed the movement. New York: The New Press.

Dale, A., \& Newman, L. L. (2009). Sustainable development for some: Green urban development and affordability. Local Environment, 14(7), 669-681. doi:10.1080/13549 830903089283

Davidson, M. (2008). Spoiled mixture: Where does state-led 'positive' gentrification end? Urban Studies, 45(12), 2385-2405. doi:10.1177/0042098008097105

Davidson, M., \& Lees, L. (2005). New-build 'gentrification' and London's riverside renaissance. Environment and Planning A: Economy and Space, 37(7), 1165-1190. doi:10.1068/a3739

Fullilove, M. (2004). Root shock: Upheaval, resettlement and recovery in urban America. New York: The Random House Publishing Group.

Gibson, K. J. (2007). Bleeding Albina: A history of community disinvestment, 1940-2000. Transforming Anthropology, 15, 3-25. doi:10.1525/tran.2007.15.1.03

Glass, R. L. (1964). London: Aspects of change (Vol. 3). London, UK: MacGibbon \& Kee.

Greenfield, J. (2016, March 23). Residents want to ensure that Paseo Trail won't be a route to gentrification. The Chicago Reader. Retrieved from https://www.chicagoreader.com/ chicago/little-village-pilsen-paseo-displacement-fears/Content?oid¹/421527919

Harvey, D. (2005). A brief history of neoliberalism. New York: Oxford University Press.

Hickey, R., Sturtevant, L., \& Thaden, E. (2014). Achieving lasting affordability through inclusionary housing. Lincoln Institute of Land Policy working paper. Retrieved from https://www.lincolninst.edu/sites/default/files/pubfiles/achieving-lasting-affordabilitythro ugh-inclusionary-housing-full.pdf

Hodkinson, S., \& Essen, C. (2015). Grounding accumulation by dispossession in everyday life: The unjust geographies of urban regeneration under the private finance initiative. International Journal of Law in the Built Environment, 7(1), 72-91. doi:10.1108/IJLBE-01- 2014-0007

Kennedy, M., \& Leonard, P. (2001). Dealing with neighborhood change: A primer on gentrification and policy choices. Washington, DC: Brookings Institution. Retrieved from https://www.brookings.edu/wp-content/uploads/2016/06/gentrification.pdf

Kern, L., \& Kovesi, C. (2018). Environmental justice meets the right to stay put: Mobilising against environmental racism, gentrification, and xenophobia in Chicago's Little Village. Local Environment, 23(9), 952-966. doi:10.1080/13549839.2018.1508204

Lees, L., Slater, T., \& Wyly, E. (2013). Gentrification. New York: Routledge.

Li, B. Y., Vitiello, D., \& Acoca, A. (2013). Chinatown then and now: Gentrification in Boston, 
New York and Philadelphia. Asian American Legal Defense and Education Fund. Retrieved from http://aaldef.org/Chinatown\%20Then\%20and\%20Now\%20AALDEF.pdf Lipsitz, G. (2007). The racialization of space and the spatialization of race: Theorizing the hidden architecture of landscape. Landscape Journal, 26(1), 10-23.

Maciag, M. (2015). Gentrification in America report. Governing. Retrieved from http:// www.governing.com/gov-data/census/gentrification-in-cities-governing-report.html

McKittrick, K. (2011). On plantations, prisons, and a black sense of place. Social \& Cultural Geography, 12(8), 947-963. doi:10.1080/14649365.2011.624280

Marcuse, P. (1985). Gentrification, abandonment, and displacement: Connections, causes, and policy responses in New York City. Washington University Journal of Urban and Contemporary Law, 28, 195-240.

Medina, J. (2013). The epistemology of resistance: Gender and racial oppression, epistemic injustice, and the social imagination. New York: Oxford University Press.

Moskowitz, P. (2017). How to kill a city: Gentrification, inequality, and the fight for the neighborhood. New York: Nation Books.

Nam, C. (2012). Implications of community activism among urban minority young people for education for engaged and critical citizenship. International Journal of Progressive Education, 8(3), 62-76.

National Association of Social Workers. (2017). Code of ethics of the National Association of Social Workers. Washington, DC: National Association of Social Workers.

Nelson, A. (2013). Greater Nashville trends, preferences and opportunities 2010 to 2025 and to 2040. Nashville, TN: Metro Nashville Planning Department. Retrieved from https:// www.nashville.gov/Portals/0/SiteContent/Planning/docs/NashvilleNext/2003\%2009\% 2019\%20Nashville\%20Trends\%20Opportunities\%202025-2040.pdf

Office of the Mayor. (2017). Housing Nashville Report. Retrieved from https://www.nash ville.gov/Portals/0/SiteContent/MayorsOffice/AffordableHousing/Housing\% 20Nashville\%20FINAL.pdf

Owen, J. (2015, October 15). Gentrification pushing some of the poorest members of society out of their homes, says study. The Independent. Retrieved from http://www.indepen dent.co.uk/news/uk/home-news/gentrification-pushing-some-of-the-poorest-membersof-s ociety-out-of-their-homes-says-study-a6695926.html

Rose, G. (1993). Feminism \& geography: The limits of geographical knowledge. Minneapolis: University of Minnesota Press.

Rotstein, G. (2015, May 21). Census shows Pittsburgh population decreasing. Pittsburgh Post-Gazette. Retrieved from http://www.post-gazette.com/local

Schusler, T., \& Krings, A. (2018). Addressing environmental gentrification: Improving environmental health for children and youth without displacement. Report prepared for the Center for the Human Rights of Children, Loyola University Chicago. Retrieved from https://www.luc.edu/media/lucedu/chrc/pdfs/Addressing\%20Environmental\% 
20Gentrification\%20Improving\%20Environmental\%20Health\%20for\%20Children\% 20and\%20Youth\%20without\%20Displacement.pdf

Schusler, T., Krings, A., Asis, D., \& Fitzpatrick, S. (2017). Brownfield redevelopment, urban greening, and gentrification: A preliminary review of literature. Report prepared for the Little Village Environmental Justice Organization.

Smith, N. (1996). The new urban frontier: Gentrification and the revanchist city. New York: Routledge.

Smith, N. (2002). New globalism, new urbanism: Gentrification as global urban strategy. Antipode, 34, 427-450. doi:10.1111/1467-8330.00249

Stake, R. E. (2006). Multiple case study analysis. New York, NY. Guilford Press.

Sturgeon, P. C. (2016, March 18). Low- and middle-income families vanish as urban neighbourhoods gentrify. Global News. Retrieved from https://globalnews.ca/news/2584050/low-and-middle-income-families-vanish-as-urban-n eighbourhoods-gentrify

Thurber, A. (2019). The Neighborhood Story Project: A practice model for fostering place attachments, social ties, and collective action. Journal of Prevention and Intervention. Advance online publication. doi:10.1080/10852352.2019.1633072

Thurber, A. (2018). Keeping more than homes: A more than material framework for understanding and intervening in gentrifying neighbourhoods. In J. Clark \& N. Wise (Eds), Urban renewal, community and participation - Theory, policy and practice (pp. 25-43). Berlin: Springer. doi:10.1007/978-3-319-72311-2

Truehaft, S. (2016). Equitable development: Apath to an all-in Pittsburgh. Oakland, CA: PolicyLink. Retrieved from http://www.policylink.org/sites/default/files/report_pitts burgh_FINAL_PDF

Twigge-Molecey, A. (2014). Exploring resident experiences of indirect displacement in a neighbourhood undergoing gentrification: The case of Saint-Henri in Montreal. Canadian Journal of Urban Research, 23, 1-22.

Wisniewski, M. (2018, April 30). So, what exactly happened to Mayor Emanuel's plan for Pilsen, Little Village bike and pedestrian trail? The Chicago Tribune. Retrieved from http://www.chicagotribune.com/news/columnists/wisniewski/ct-met-paseo-trail-gettingar ound-20180426-story.html

Zuk, M., Bierbaum, A. H., Chapple, K., Gorska, K., Loukaitou-Sideris, A., Ong, P., \& Thomas, T. (2015). Gentrification, displacement and the role of public investment: A literature review (No. 2015-55). San Francisco, CA: Federal Reserve Bank of San Francisco. 
